\title{
Medical Information Practices Across the Pharma Industry: What Can We Learn from Benchmarking Surveys?
}

\author{
Ina Shah, PharmD ${ }^{1}$ - Izzat Janajreh, PharmD, $\mathrm{RPh}^{1} \cdot$ Stacey M. Fung, PharmD ${ }^{2}$
}

Published online: 12 November 2020

(C) The Drug Information Association, Inc 2020

Within the pharmaceutical industry, Medical Information (MedInfo) departments provide scientific, therapeutic, and product expertise to support healthcare professionals, patients, and payers in making informed patient care decisions [1-4]. MedInfo departments play an integral role in evaluating evidence-based medicine, developing medical content, and responding to unsolicited medical information requests about a company's product(s) by providing relevant clinical data to healthcare providers and consumers.

Over the years, the role and scope of MedInfo departments have changed from early published descriptions (such as Curran's progress report of drug information from 1970 to 2000 [1], Hopkins and colleagues 1999 benchmarking report of medical information practices [2], and a description of a core curriculum for professionals practicing in MedInfo departments described by Graves and Baker in 2000 [3]). Recent reports describe expanded activities highlighted in this special issue of Therapeutic Innovation \& Regulatory Science (TIRS).

The growth and development of MedInfo practice over the years happened within a rapidly evolving and changing healthcare landscape within a highly regulated environment. Changes include increases in the number of medical inquiries, complexity of inquiry topics and therapeutic agents, expectations to provide prompt responses, digital technology advancements, and more highly educated and knowledgeable patients and caregivers. MedInfo department activities are centered on the knowledge and expertise that the personnel

Ina Shah

ina.shah@allergan.com

Izzat Janajreh

Izzy.Janajreh@allergan.com

Stacey M. Fung

stacey.fung@gilead.com

1 AbbVie, 5 Giralda Farms, Madison, NJ 07940, USA

2 Gilead Sciences, Inc., 333 Lakeside Drive, Foster City, CA 94404, USA have relative to the product or therapeutic area. These groups perform activities throughout a product's development and life cycle. From supporting the product via oversight of a MedInfo contact center and provision of medical information to healthcare professionals and patients to performing and/or supporting promotional material review, field medical materials development, scientific meeting support, publication planning, medical education, clinical trial recruitment, product labeling support, product dossier development, maintenance of medical information self-service websites, and participating in training of sales or other internal partners $[4,5]$. In addition, the MedInfo teams are valued by internal business partners as the groups that are taking on more active roles in ensuring the clinical data integrity of promotional materials, field medical team materials, and product dossiers, as well as sharing medical and customer insights to shape medical strategy. The expansion of the roles globally also signifies the advancement and growth of the services provided [6].

While studies have reported that healthcare professionals and patients value the medical content provided by MedInfo departments measured by reported usage of information and/or action taken [7, 8], there is still a lack of awareness among healthcare professionals (HCPs) and patients about pharmaceutical industry MedInfo services. Individual companies have been unsuccessful in addressing this knowledge gap and bringing visibility to the value of pharmaceutical industry MedInfo services [9, 10]. A consortium of USbased pharmaceutical company MedInfo departments, such as phactMI ${ }^{\mathrm{TM}}$ (Pharma Collaboration for Transparent Medical Information), has the ability to increase awareness of and enhance access to relevant, evidence-based, and timely medical information [11]. phactMI ${ }^{\mathrm{TM}}$, a non-profit $501 \mathrm{c}(6)$ organization, came together to discuss common challenges across the industry relating to access to medical information. phactMI was founded by 19 pharmaceutical companies, and membership has currently grown to 31 companies: AbbVie/Allergan, Alexion, Amgen, Astellas, AstraZeneca, 
Bayer Pharmaceuticals, Bayer, Biogen, Boehringer Ingelheim, Bristol-Myers Squibb/Celgene, Eli Lilly and Company, EMD Serono, Esperion, Genentech, Gilead Sciences, GlaxoSmithKline, Genmab, Incyte, Ipsen Biopharmaceuticals Inc., Janssen, Jazz Pharmaceuticals, Merck, Novartis, Novo Nordisk, Otsuka, Pfizer, Sandoz, Sanofi, Shire/Takeda, Sunovion, and Vertex [11]. The membership of phactMITM companies consists of small (fewer than 10,000 employees), mid-size (fewer than 80,000 employees), and large-size (more than 90,000 employees) [12] companies across the industry representing pharmaceutical and biologic products as well as devices. phactMI ${ }^{\mathrm{TM}}$ strategic objectives have focused on shaping the future of MedInfo practice, being the go-to provider of medical information via a web portal, building a MedInfo community, and catalyzing innovation with new services and communication channels for customers.

phactMI ${ }^{\mathrm{TM}}$ conducted a comprehensive benchmarking survey focusing on all aspects of medical information, as previous MedInfo department benchmarking surveys were not all-inclusive and focused on specific aspects of medical information such as call center [13] or promotional review $[14,15]$. Benchmarking surveys are good indicators for comparing an organization's processes and metrics to best practices from other organizations [16].

The objective of the phactMI ${ }^{\mathrm{TM}}$ 's benchmarking survey is to leverage collective insights and experiences of MedInfo departments across the pharmaceutical industry to explore the development and expansion of MedInfo services. By analyzing key trends, MedInfo departments may enhance their strategies to provide optimal support for their overall organizations and evolve practices to incorporate new services and activities to enable enhanced patient treatment decisions and improve the quality of an MedInfo organization's processes, products, and programs to support customers.

An electronic survey with approximately 300 questions was delivered to 27 member companies between December 12, 2017 and February 20, 2018. A committee of more than ten MedInfo leaders from member companies identified the topics for inclusion in the survey, developed the survey questions, and provided feedback during the implementation of the survey. The survey consisted of open- and closedended questions and was divided into nine topics: company background, organizational structure and resources, inquiry management, content development, technology and website, product support, key performance indicators, decision makers and other services. The survey covered a 1-year time frame and is scheduled to be repeated periodically with member companies, with the technology portion to be repeated annually.

The final survey results were disseminated to the member companies. Each member company received a dashboard with their individual company data in addition to anonymized total data from all the participating member companies. In addition, a series of manuscripts, press releases, and congress presentations were planned based on different sections of the survey so that findings could be shared with non-member companies and to raise awareness.

In this special issue of TIRS, a series of articles developed from the phactMITM benchmarking survey results are described. Before delving into the nuances of how MI departments differ among the phactMI ${ }^{\mathrm{TM}}$ member companies, it is vital to consider how organizational structure and resource management contrast among respondents. From the benchmarking survey results, Marasigan and colleagues identified the need for MedInfo departments to modify their structure and resourcing over time to continue showing value to the overall organization. It was noted that while all 27 companies surveyed identified themselves as global organizations, and the majority were involved with pharmaceuticals, biologics, and over-the-counter (OTC) products, the size of the organizations, as mentioned before, and the products supported (from five reporting more than ten to seven reporting more than 50) varied. Additionally, variability was noted in the organizational structure of these departments [12].

However, a commonality among most of the survey participants included the strategy to outsource some aspect of MedInfo activities, which allowed for different resourcing strategies to take place [12]. These results resemble previously reported survey findings [13], allowing the authors to conclude that most of the structure and operations of MedInfo departments in the USA have remained similar despite the evolution of the pharmaceutical industry over time [12].

MedInfo departments have strategies to manage resources to offer efficient product support. Patel et al. reported that most companies considered the product lifecycle when planning product support. Pipeline, launch, and active/current products were supported by nearly all MedInfo departments. In most departments, MedInfo support did not decrease until the products matured. To assist with decision-making, key performance indicators (KPIs) are utilized by most companies. MedInfo departments use KPIs to convey efficiency and workload management to senior leadership. These metrics allow departments to make decisions on the allocation of resources and support for other services. By displaying efficiency, MedInfo departments can assist with many other services, as shown in this survey, to enhance their overall value to the organization [17].

Effectively managing and responding to inquiries from HCPs and consumers are of paramount significance to a MedInfo department. Byun et al. evaluated inquiry management and MedInfo department responses, including the different approaches such as internal, outsourcing, or mixed models towards contact centers and the wide array of channels through which customers have to communicate with 
these centers. Many departments offered varied feedback to the volume and types of inquiries handled. Most departments look at the rapidity of completing different inquiry types to requestors and who the requestor is (HCP, consumer, etc.) as well as of optimizing resources to fulfill them. Information regarding the content length, format, and other features were also gathered from this survey [18].

The final two articles presented focus on two vital concepts where MedInfo departments can show value to their overall organizations: providing assistance to healthcare decision makers (HCDMs) in their evaluation of economic outcomes and clinical effectiveness of different drugs as well as how MedInfo departments can enhance delivery of this information to customers given all the technological advances available today. D'Ascoli et al. provided a historical perspective on healthcare expenditures, the evolution of healthcare insurance companies, managed care organizations, and pharmacy benefits managers, and on how legislation has evolved over time to provide more clarity on the type of information MedInfo departments may provide. Advancements, such as the Academy of Managed Care Pharmacy (AMCP) dossier, provide standardized templates for how MedInfo departments can respond to HCDMs for requests. Some of the responses from the benchmarking survey that D'Ascoli et al. evaluated included how HCDM requests are received, the materials with which MedInfo departments respond to specific requests, resources and partnerships for creation of payer-focused materials, development of pre-approval and post-approval HCDM content and tools, and the delivery methods of content to customers. A key takeaway from the evaluation of these questions was that a follow-up benchmarking survey may show an increase in the creation of pre-approval dossiers as the understanding of legislative updates and the necessity for HCDMs to plan and budget for future coverage and/or reimbursement decisions increases with time [19].

A majority of companies do not provide payer materials online due to expense, workload, and low number of requests [19], even though Patel and colleagues highlighted that 74\% of the companies surveyed provide MedInfo through a website (an additional 22\% answered that they planned on doing so in the future). With the advancements in technology, it is not surprising that more HCPs and consumers are requesting MedInfo through digital channels. Understanding this, it was valuable to capture how different MedInfo departments were providing access to medical information via digital channels. Key topics included how accessible the information is on current websites, available content type, the functions of the website, utilization of search engine optimization, and unique features provided to customers. Understanding how these factors drove website traffic, internal communications and analytics, and other quantifiable results would offer insight into how significant an impact MedInfo departments can have in the digital arena. As the results indicated, traditional website features are commonly available on MedInfo department websites; however, innovative technologies are currently less featured and need to be addressed [20].

This benchmarking survey was successful in showcasing ideas and functions that are widely accepted and used across phactMI ${ }^{\mathrm{TM}}$ member companies. Although the healthcare landscape is constantly changing, the survey findings illustrate that MedInfo departments continue to focus on providing some of the same core functions that have been described in previous surveys, but they also have adapted to deliver additional services. By leveraging the insights and experiences captured from the phactMI ${ }^{\mathrm{TM}}$ benchmarking survey results, MedInfo departments can optimize their efficiency with a thorough look at internal practices, metrics, and technological advancements available. Furthermore, the benchmarking survey findings may assist in evaluating different strategies to take on additional services and activities to enhance the MedInfo department's value to the overall organization. Seeking and creating innovative methods of providing medical information will pose new challenges; however, it is essential to do so in the best interest of optimizing patient care decision-making to the customer.

\section{References}

1. Curran CF. A progress report: Drug information from 1970 to 2000. Drug Inform J. 2000;34:1355-63.

2. Hopkins F, Galligher C, Levine A. Medical affairs and drug information practices within the pharmaceutical industry: Results of a benchmarking survey. Drug Inform J. 1999;33:69-85.

3. Graves DA, Baker RP. The core curriculum for medical communications professional practicing in the pharmaceutical industry. Drug Inform J. 2000;34:995-1008.

4. Cadogan AA, Fung SM. The changing roles of medical communications professionals: Evolution of the core curriculum. Drug Inform J. 2009;43(6):673-84. https://doi.org/10.1177/00928 6150904300605.

5. Bordoloi $\mathrm{P}$, et al. Medical information services: How are we trending? Ther Innov Regul Sci. 2014;48:15-21.

6. Giffin SA, Shah R, Soloff A, Vaysman AM, Oregper J, Gazo A, et al. Pharma collaboration for transparent medical information (phactMI) benchmark study: Trends, drivers, success factors, and value of globalization in medical information. Ther Innov Regul Sci. 2018;53(3):332-9. https://doi.org/10.1177/216847901877992 0 .

7. Fung SM, Chang DY, Patel-Romero R, Suchodolski M. Survey of health care practitioners' preferences for medical information: Collective insights for impacting patient care. Ther Innov Regul Sci. 2016;50:569-76.

8. Fung SM, Sud C, Suchodolski M. Survey of customers requesting medical information: Preferences and information needs of patients and health care professionals to support treatment decisions. Ther Innov Regul Sci. 2020;54:75-84.

9. Sermo @WorldOne. Medical Information Awareness Survey, June 2014. New York, NY. 
10. Manhattan Research. Taking the Pulse1 U.S. Survey 2015. Decision Resources Group. New York, NY.

11. phactMI: Pharma Collaboration for Transparent Medical Information website. https://www.phactmi.org/PortalAboutUs.

12. Marasigan K, Doshi S, Fung S. Pharma collaboration for transparent medical information (phactMI) benchmark study: Results of organizational structure and resourcing of medical information services in support of building departmental strategies. Ther Innov Regul Sci. 2020. https://doi.org/10.1007/s43441-020-00143-1.

13. Guillot P, Fung SM. Pharmaceutical medical information contact centers: Results of three benchmarking surveys. Ther Innov Regul Sci. 2010;44:569-79.

14. Bonk L, Kothari M, Andrikanich AS, Yang E. The role of pharmaceutical medical information in promotional review: Three benchmarking surveys. Ther Innov Regul Sci. 2012;46:107-14.

15. Paquette-Lemieux E, Hays $S$, Gaspo R. US medical information websites benchmarking: How is the industry fairing in usability? Ther Innov Regul Sci. 2019;53:340-8.

16. Starr S. Survey research: We can do better. J Med Libr Assoc. 2012;100(1):1-2. https://doi.org/10.3163/1536-5050.100.1.001.
17. Patel M, Jindia L, Fung S, Kadowaki R, Marasigan K. Pharma collaboration for transparent medical information (phactMI) benchmark study: Trends, drivers, and value of product support activities, key performance indicators, and other medical information services: Insights from a survey of 27 US pharmaceutical medical information departments. Ther Innov Regul Sci. 2020. https://doi. org/10.1007/s43441-020-00162-y.

18. Byun J, Jong JA, Gangat A, Flowers T, Gazo A, Shah I. phactMI benchmarking survey on content development and inquiry management. Ther Innov Regul Scii. 2020. https://doi.org/10.1007/ s43441-020-00137-z.

19. D'Ascoli A, Gazo A, Yueh S, Egri F, Akanda S. phactMI benchmarking survey: Analysis of 27 medical information departments responses to inquiries from health care decision makers. Ther Innov Regul Sci. 2020. https://doi.org/10.1007/s43441-020-00148 -w.

20. Patel P, Gaspo R, Crisan A, Lee J. Where are we now in providing medical information in the digital space? A benchmark survey of phactMI member companies. Ther Innov Regul Sci. 2020. https ://doi.org/10.1007/s43441-020-00222-3. 